\title{
Research on Cold Chain Logistics Traceable System for Fresh Agricultural Products
}

\author{
Xingang Weng1, Hui Yang1, Lei Wang2 \\ ${ }^{1}$ Beijing Wuzi University, Beijing, China \\ ${ }^{2}$ Beijing Benz Automotive Co., Ltd, Beijing, China \\ Email: anjiuyi@126.com
}

Received 30 September 2015; accepted 12 December 2015; published 15 December 2015

Copyright (C) 2015 by authors and Scientific Research Publishing Inc.

This work is licensed under the Creative Commons Attribution International License (CC BY). http://creativecommons.org/licenses/by/4.0/

c) (7) Open Access

\begin{abstract}
The trace of agricultural products logistics process is an important part of supply chain full retrospective. Factors of quality and safety of agricultural products run throughout the agricultural products from production to processing, packaging, storage, transportation and sales. For ensuring the safety of agricultural products, establishing full traceable system covering production, processing and distribution are particularly important. Based on the analysis of the connotation of the cold chain logistics system of agricultural products, this article analyzes cold chain logistics traceable system's framework and key elements, and further puts forward the path choice of cold chain logistics traceable system's implementation for agricultural products.
\end{abstract}

\section{Keywords}

Fresh Agricultural Products, Cold Chain Logistics, Traceable System

\section{Introduction}

The key of cold chain logistics for agricultural products lies in ensuring the quality of agricultural products and their safety. With the series of quality safety of agricultural products in China, people put forward higher requirements for the products' security, thus guarantee that the quality safety of agricultural products is crucial. Factors of quality and safety of agricultural products run throughout the agricultural products from production to processing, packaging, storage, transportation and sales. For ensuring the safety of agricultural products, establishing full traceable system covering production, processing and distribution are particularly important. Therefore, the establishment of traceability of the cold chain logistics for agricultural products is particularly important. Based on this background, this article introduces the traceable system of cold chain logistics for agricultural product, and hopes that this can play a role in the quality assurance of agricultural products. 


\section{Intension and Extension of Cold Chain Logistics Traceable System for Agricultural Products}

\subsection{Understanding of Traceability}

“Traceability" was firstly applied in the automotive industry [1]. The trace added to agricultural products' quality and safety management was gradually developed in the 1980s after the mad cow incident, firstly put forward by France and some other EU countries [2]. In July 2000, the European Parliament and the Council of the European Union launched (EC) Decree NO 1760/2000. "On the establishment of bovine animals inspection and registration system and the label of beef and beef meat products", for the first time raised beef products' traceable requirements from the viewpoint of legal. Shanghai issued "Interim measures for the supervision of edible agricultural products safety" in July 2001, proposing establishment of traceability about marketing archives in circulation, formally applied the traceable system in the field of quality and safety of agricultural products in China [3].

Traceability is a basic concept. "Traceability", also known as the origin, the concept stems from quality management standards. As early as $1987 \mathrm{~s}$, it is described as "by identifying to track or record an entity history, purpose and location" in ISO 8402. The essence of "traceability" is information of recording and tracking systems. The definition of Codex Alimentarius Commission (CAC) is the ability of tracing food in production, processing and circulation of any particular stage [4]. International food standards (Codex) defined "traceability" as: ability of tracing food in production, processing, storage and circulation of any process, to maintain the integrity and sustainability of the food supply chain information flow. EU "General Food Law" (EC178/2002) refers to the tracking capabilities of food, feed, consumption of livestock and all substance has the potential to be food or feed ingredients in all the respects of production, processing and sales. In China, "The quality management and quality assurance-glossary" (GB/T6582-1994) define the traceability as: the ability of tracing the history, application or location of the target object. Good agricultural practice (China GAP) requirements of traceability are: the ability of proving the history, use and location of object by records (that is, sources of materials and components, product processing history, product sales and delivery arrangements, and so on) [5].

\subsection{Intension of Cold Chain Logistics Traceable System for Agricultural Products}

According to domestic and foreign scholars defining the connotation of traceability, this article defines cold chain logistics traceability for agricultural products as: the capabilities of identifying through the record or tracking agricultural products "from farm to fork" activities during the entire cold chain logistics [6]. Aimed at querying the main body responsibility about problems of logistics as quickly and efficiently as agricultural products' quality issue arises, products recall, if necessary. And implement the sanctions, thereby improving the quality of service levels. Agricultural products' quality and safety traceable system has three main functions: when agricultural products' security problems occur, we can quickly go back to the link which has problems; we can quickly recover agricultural products are not sale or consumption; we can monitor and identify long-term hazard about the impact of unconscious to human health, animal or environment. Cold chain logistics of agricultural products subject is one of the important participants in the agricultural products supply chain, its safety is an important part of quality and safety of agricultural products. Therefore, cold chain logistics of agricultural products' quality and safety traceability is an important part of agricultural products quality and safety traceability [7].

The cold chain logistics traceable system for agricultural products is using modern network technology, database management technology and bar code technology, to collect, record, sort, analyze, and entry information about agricultural products from the production, processing, packaging, transportation to storage and sales and so on, eventually can query through the terminal electronic equipment of quality guarantee system. The cold chain logistics traceable system for agricultural products (food traceable system) established based on supply chain management is an organic integrity of a series of mechanism. Through specific of registration recognition system platform management and data collection covers whole supply chain, from origin information of raw materials, processing process, circulation process of products, to eventual users, making agricultural products supply full process completely transparent, controllable, visualized. It can provide accurate and detailed information of security for consumers and increase consumer confidence, which including from upstream to downstream supply chain tracking (racking, top-down traceability) and from downstream to upstream traceability 
(racing, bottom-up traceability) [8]. Racking points to downstream traceability, that is, from supply chain upstream to downstream, from farms, food raw materials suppliers, processors, transporters, to sellers, mainly used to find the cause of quality problems and determine the origin and features of products. Racing refers to the upstream traceability, from supply chain downstream to upstream, that is, when consumers find agricultural products have quality problems at the point of sale, they can track here to search the final problem, mainly used for the recall of agricultural products with quality problems.

\section{Analvsis of Cold Chain Logistics Traceable System's Framework and Key Elements}

The cold chain logistics traceable system for agricultural products is using modern network technology, database management technology and bar code technology, to collect, record, sort, analyze, and entry information about agricultural products from the production, processing, packaging, transportation to storage and sales and so on, eventually can query through the terminal electronic equipment of quality guarantee system [3].

\subsection{Analysis of Cold Chain Logistics Traceable System's Framework}

The cold chain logistics traceable system for agricultural products uses technology as means and based on regulations standard. Its construction regards the central, province, and city multilevel traceable management platform as core, the agricultural production, processing, wholesale, retail, consumption link and the "production-sales docking” core logistics enterprise traceable system as support, the management of logistics traceable information chain integrity as focus, aiming to achieve agricultural cold chain logistics service can track origin source, check where it is, investigate responsibility. And strengthen the combination of government public service, industry self-discipline, consumer supervision mechanism, improve the safety ensuring ability of the cold chain logistics processes (as shown in the following Figure 1).

Government monitoring platform: platform of government regulation is the main carrier of tracing management. Government departments carry out traceable management and public information services through the platform. Government's traceable management platform is the data exchange between the city centers, the centralized management center of national traceable information, as well as the command and dispatch center of

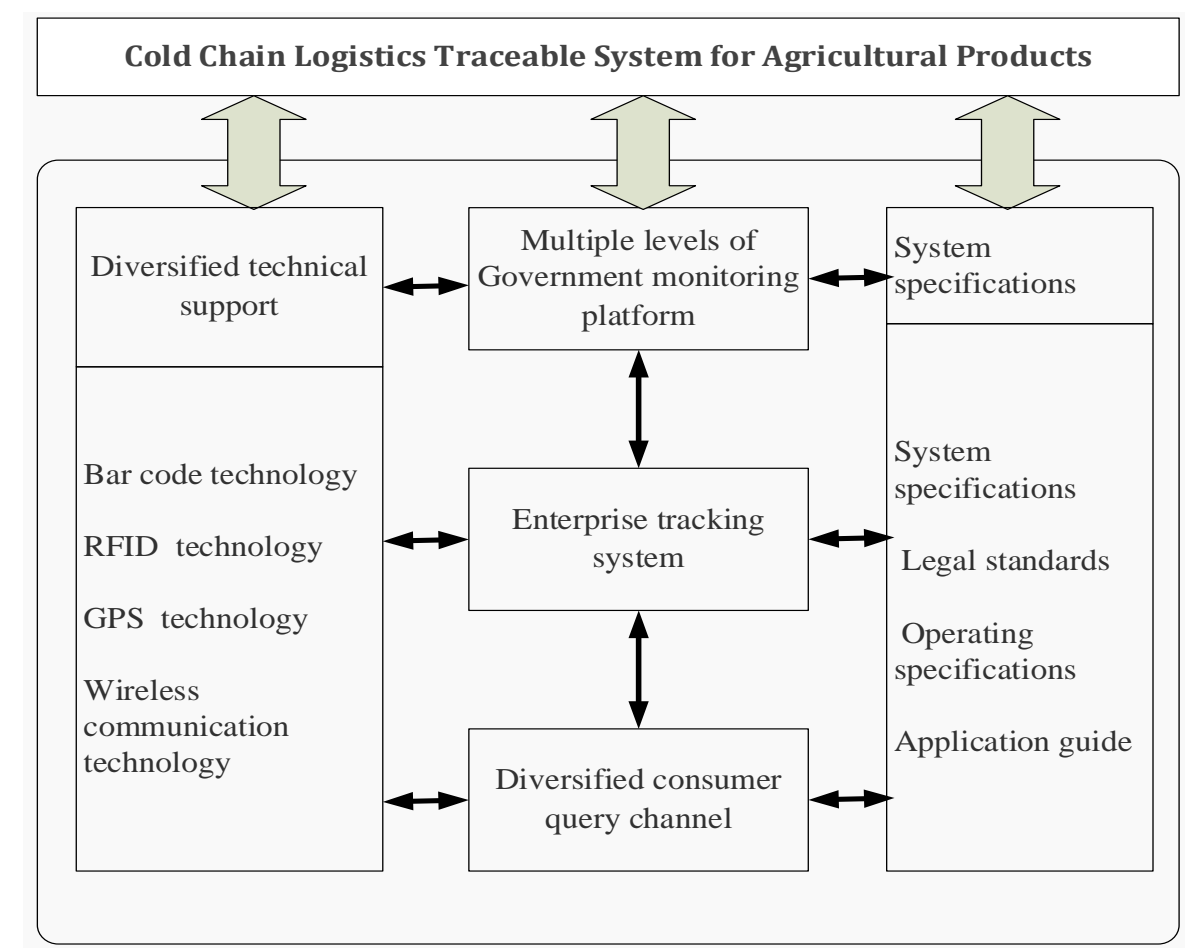

Figure 1. Framework of cold chain logistics traceable system for agricultural products. 
day-to-day running of the national traceable system. Its main functions are: summarize traceable information, manage and evaluate the traceable system, comprehensive analysis of traceable information, provide the public information service related to traceable information and issue and warnings information of agricultural products. According to the national meat vegetable circulation traceable system framework set forth in "the construction specifications of national meat vegetable circulation traceable system" issued by Ministry of Commerce, tracing management platform of the Government including the Central, provincial and municipal levels, formed national traceable management system that connect, coordinate and functional complementation from top to bottom, as the carrier of Government to carry out circulation traceable management and the public information service.

Enterprises' traceable system: enterprise according to both the general requirements of national agricultural circulation traceability and the need of enterprise's internal information transformation, to construct the traceable system among agricultural production enterprise, agricultural processing enterprise, wholesale market, retail market, and agricultural cold chain logistics enterprise that regard these enterprise as service object, and seamlessly connect with the national traceable management platform. As information collection point of agricultural cold chain logistics traceability, while play a role of specifying logistics service process in all links.

Consumer query system: establish retrospective inquiry system that focuses on consumer information and consumption management in consumption link.

Consumers can search information through a dedicated terminal installed in the retail market, open telephone text messages, the Internet, telephone hotlines and other accesses to query information about the circulation of agricultural products.

Group consumers query is mainly refers to groups consumer units (enterprises, government agencies, schools, restaurants, meat vegetable processing plant, etc.) set up trace query system that regards the purchase and acceptance as the core.

\subsection{Key Information's Analysis of Cold Chain Logistics Traceable System for Agricultural Products}

Under current agricultural product supply chain structure and cold chain logistics organizational mode in china, participants in cold chain logistics of agricultural products include: producer that consider farmers as the main, street pin households, the farmers' cooperative organizations, processing companies and middlemen of various nature, all types of retail terminals, professional cold chain logistics enterprises. Logistics link throughout the whole agricultural cold chain. In the process from agricultural production enterprise to processing enterprise and from processing to retailers, in current China the general mode of cold chain logistics is self-run logistics (under this mode logistics subject including: producers, and street pin households, and farmers cooperative organization, and processing companies and middlemen of various nature, all types of retail terminals), and social outsourcing logistics (under this mode logistics subject including: carrier enterprise, and cold storage operators, and thirdparty cold chain logistics enterprise).

In the cold chain of agricultural products, logistics is the link connecting production and marketing. Many agricultural products safety problems occur in the logistics link. Information about logistics is very important for agricultural products traceable system, which including two core components: transportation and distribution, storage.

\subsubsection{Transportation and Distribution}

Transportation and distribution links are major nodes contacting farmers (base), agricultural product processing plants and distributors (wholesalers and retailers).

The supply of agricultural products between farmers (base) and the processing plants, as well as between processing plants and sellers all should be done through the transportation and distribution, and the relevant information in transportation and distribution is of importance to ensure the quality of health and safety. Hence, the carrier is responsible for providing agricultural products transportation and distribution management information on the way and carrier specific information.

Transportation and delivery management information includes carriers' name, mode of transport, details of delivery means, and health conditions, information about agricultural products carried and transaction information (delivery/arrival places and dates, quantities, documentation, etc). Carriers' information includes carriers' name, company codes, business qualifications, contacts etc. 


\subsubsection{Storage}

Storage is mainly for agricultural products. Although there is no complex process in this link, it is important to the impact on health quality and security of agricultural products and there is also a risk here. In the traceable management of products, the store places need to be checked and archive the information in the previous link, and should provide products' information, goods number, storage conditions and the way, packaging type, delivery/shipping date, storage locations or workshop, working people information, customer information. Products need to be added with traceable information label in this link.

\section{Analvsis of Cold Chain Logistics Traceable Svstem's Implementation Mode and Benefit Parties for Agricultural Products}

\subsection{Analysis of Cold Chain Logistics Traceable System's Implementation Mode for Agricultural Products}

\subsubsection{Government-Dominated}

Government-dominated traceable system means the government regards serving the agricultural products quality and safety supervision as its goal, ensuring security of consumption as the purpose. Governments have invested in national levels of cold chain logistics traceable quality information exchange platform for agricultural products, and encouraged enterprises to establish businesses internal traceable system in the form of government subsidies and preferential policies to establish and improve the traceable system.

In Beijing, for example, Beijing Municipal Government traceable system for vegetable quality and safety traceability is firstly and foremost in order to solve the problems of agricultural products quality and safety management in Beijing, secondly vegetable quality and safety traceability can improve the characteristics of suburb agricultural products market competitiveness and protect the quality of agricultural products of the brand. Finally, vegetable quality and safety traceability is the urgent demand of developing export agriculture. Because of this, Beijing Municipal Government gives high priority to establish agricultural products traceable system, and support with a high degree in form of finance and policy. In Beijing funds required for traceable system construction and operation adopt "Government subsidies, market operation" approach. During the period of system's construction: mainly by Government subsidies, marketing operation as a supplement, namely, the Government invests construction, and enterprises participating in pay service fees symbolically. After the formal operation of the system: mainly by marketing operation, supplemented by Government subsidies, namely enterprises pay service charges for system requirements, and the government subsidy properly. Early in the traceable system established, the Government's high attention and input to the establishment of traceable systems in Beijing played a very important role (as shown in the following Figure 2).

\subsubsection{Enterprises-Led}

The implementation of enterprises-led traceable system mainly depends on the enterprises' consciousness. Enterprises accord to their own development needs and undertake the main costs and expenses of traceable system. The implementation of this mode requires enterprises' full awareness about quality and safety of cold chain logistics for agricultural products and their financial strength. Traceable system in the implementation of an enterprise cannot be isolated in one system, because it is feasible and realistic until combined with other management tools. Only enterprises with certain management and conditions have the prerequisite and basis for traceability (as shown in the following Figure 3).

\subsection{Analysis of Cold Chain Logistics Traceable System Benefit Parties for Agricultural Products}

Cold chain logistics traceability of agricultural products involves multiple actors, including suppliers of raw materials, agricultural producers, processors of agricultural products, sales of agricultural products, consumers, quality certification institutes, government departments and third-party tracing platform providers.

Producers undertake the primary production and supplies of agricultural products, and it is the basis link to ensure the quality of products, improve the level of security and increase the supply of security information. Currently in our country the spot of agricultural products are dispersedly produced, and the storage in early picking period is improperly, trading facilities falls behind, and poor environment. 


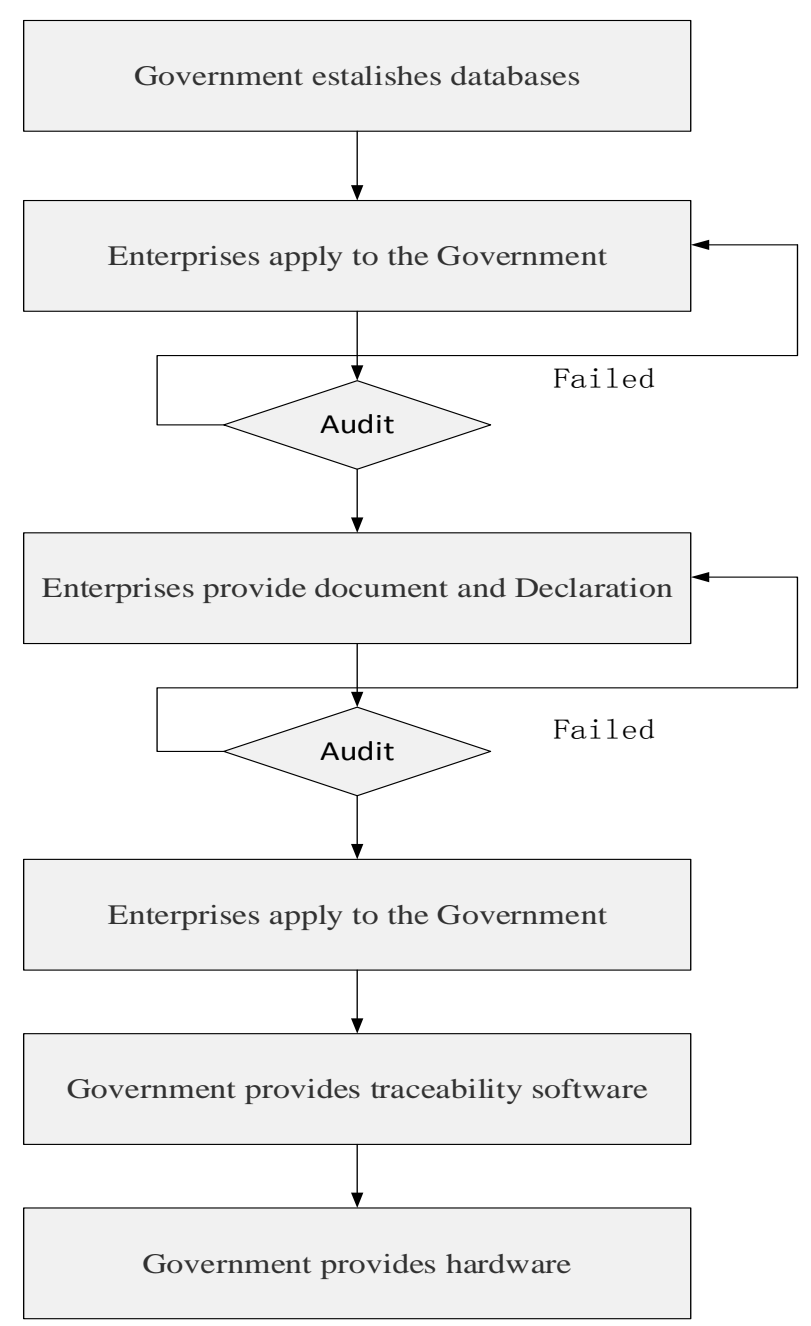

Figure 2. The process of government-dominated cold chain logistics traceable system's implementation model for agricultural products.

Fresh agricultural product processor is the subject to achieve product conversion, value added and security of supply.

In cold chain of agricultural products, the information connection between processing places and producers is usually the bottleneck to achieve full traceability. Processing stage makes raw agricultural products into the sales phase of commercialization of agricultural products. After inspection, processed products have to pass logistics link into the sales link, and it is a very important part of agricultural products traceability as well as an important part of security.

The main agricultural products trade enterprises include agricultural products markets and supermarkets. In China, agricultural products markets are the important sale links, especially the rural markets. But because of inadequate facilities and cold chain management is not standardized, it is a major blind spot for cold chain logistics traceability of agricultural products. Retail is the final link that delivering products to consumers, which is also the last mark to track.

Cold chain logistics enterprises offer logistics activities across the entire cold chain of agricultural product, from producers to processors and processors to retailers. In our country, the general mode is self-run logistics and social outsourcing logistics, which take enterprises upstream and downstream rational organization and mutual supervision.

Government departments need to achieve effective management of the traceable system as a whole. The Government should not only focus on the origin of agricultural products and health issues, but also carry out ef- 


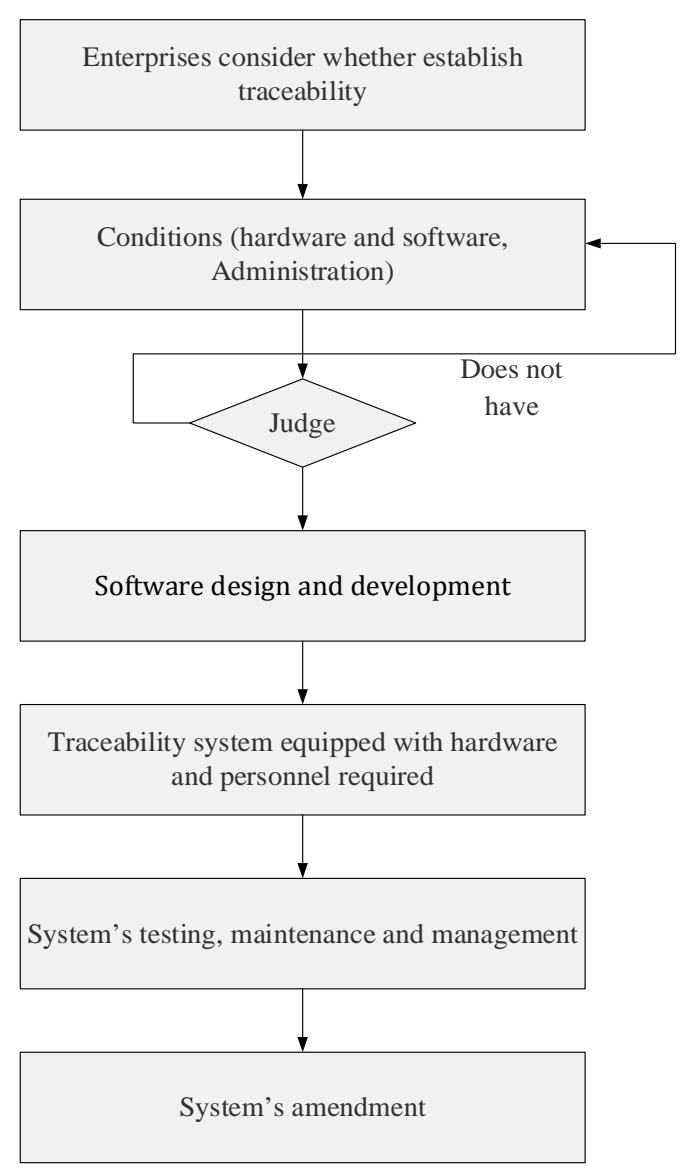

Figure 3. The process of enterprises-led cold chain logistics traceable system's implementation mode for agricultural products.

fective supervision on cold chain logistics. Government departments should strengthen the full management of the traceable system, not only monitor temperature, sanitation of a node, but also establish a monitoring system to track the entire system. In addition, intensify law enforcement on agricultural safety, transportation, storage, health and quarantine, resolutely investigate and punish violators and put an end to agricultural products' secure risks.

\section{Path Choice of Cold Chain Logistics Traceable System Implementation for Agricultural Products}

The situation that agricultural products circulation have to through multiple links and the current regulation system in our country determine sector segment management in cold chain logistics traceable system for agricultural products, which leading to hard coordination and inefficient regulation. Existing cold chain logistics traceable system for agricultural products mainly led by the Government departments, who promote traceable system’s establishment and promotion in the form of various types of project funding. Learning from foreign experience and combined with the development in our country, the construction of cold chain logistics traceable system should be driven by the innovation in management, mode and technology and adhere to sustainable path.

\subsection{Analysis of Operation Control Factors about Cold Chain Logistics Traceable System for Agricultural Products}

\subsubsection{Institutional Environment of Cold Chain Logistics Traceable System for Agricultural Products}

Since 2001, China’s agricultural products traceable system started. Farm products safety supervision and man- 
agement departments designed to begin building a traceable system and standards out of public service and safety regulation, especially the State enacted "Quality Safety of Agricultural Products" and "Food Quality and Safety Act” two basic laws, which promote China's agricultural product traceable system's construction strongly. However, secure system and standard legal system of agricultural products in China are not sound enough and lack of relevant regulations and standards, lags behind the international standards and reality, which making the implementation of traceable systems lack of laws and regulations and policy, severely restricting the establishment and perfection of agricultural products traceable system.

\subsubsection{Subject Behavior of Cold Chain Logistics Traceability for Agricultural Products}

The construction of agricultural cold chain logistics enterprises includes many subjects. Based on the structure of agricultural cold chain logistics traceable system and many scholars research results, we know the government departments, cold chain logistics service providers and consumers can play main roles in supply chain of agricultural cold chain logistics construction. The run dynamic model of agricultural cold chain logistics traceable system can display relationship between the three roles (as shown in the following Figure 4).

Government's main responsibilities in the implementation of traceable system (system) are regulation and incentives, that is, the government builds pressure and motivation from outside to improve quality and safety of agricultural products and inspire and restrain the enterprises' behavior in the supply chain. Judging from developed countries, the Government plays a more important role in the establishment of agricultural products quality and safety traceable system. The Government plays the same irreplaceable role in cold chain logistics traceable system of agricultural products in China. In our country, the construction of agricultural products' traceable system is dominated by Government departments, Business Administration Department, Ministry of Agriculture and the Ministry of Commerce issue a series of regimes and guidelines, and then combine industry leaders to use policy and funds for demonstration and promotion of traceable systems. On the process of agricultural products supply chain, quality and safety information is asymmetric, so Government and consumers are limited to information, which causes potential safety risk to those who are limited to information and the community as a whole. Mandatory obligations should be given to the cold chain logistics providers of agricultural products, which is one of the main means that the Government balance information and carry out effective supervision.

As important participants and beneficiaries of the traceable system, the behavior of consumers plays an important role to the establishment of cold chain logistics traceable system for agricultural products. Based on the research literature, we find that consumers are concerned about the quality and safety of agricultural products and expect to attain traceable information provided by government departments (Industry and Commerce, Quality Supervision Department) or professional authorities. But consumers' awareness and willingness to pay for cold chain logistics traceability of agricultural products is not high, which weaken the ecological system of cold chain logistics traceable system for agricultural products. Based on researches about consumers' willingness to pay

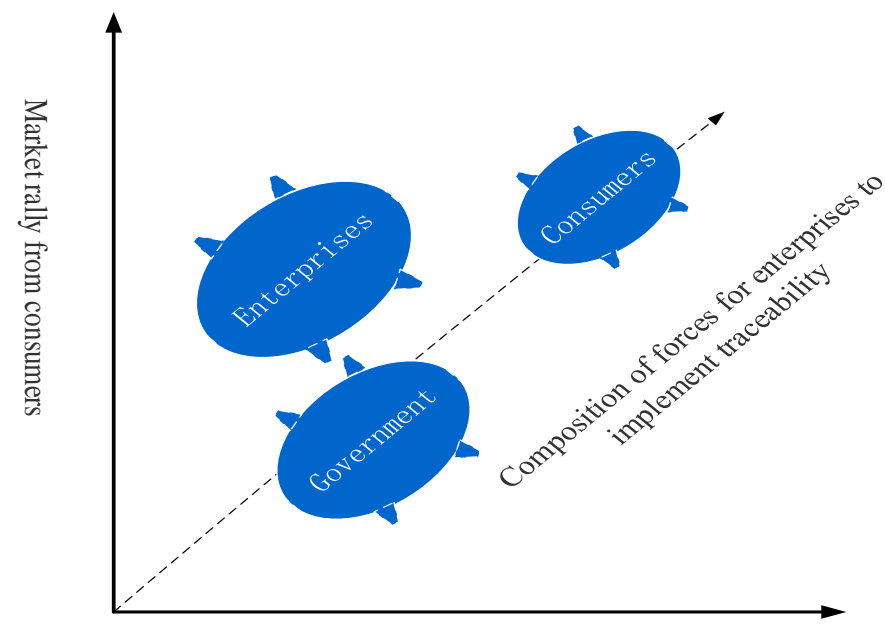

Regulation thrust from Government 
for agricultural products that can be tracked, we find education degree and income level are the primary factors that determine consumers to purchase agricultural products can be tracked. These factors determine consumers' cognitive level of products can be tracked and evaluation of importance on products traceability's implementation and agreement on the idea that products can be tracked are more secure than those cannot be tracked. The above cognition has further affected the consumer's purchase intention. From the research on situation of implementing traceable system of agricultural products in China, we find a number of consumers tend to purchase agricultural products in large cities and international markets have a certain demand of traceable agricultural products, which has driven some agricultural enterprises to create the initiative to establish the internal traceable system out of the market demand and competitive advantage of enterprises, and this also confirm the results. In agricultural supply chains, consumers' expectations for the traceable agricultural products are the basis that the Government and enterprises should pay attention to and make trade-offs. Government and enterprises should adopt effective measures so that consumers can cognize traceable system and consumers are willing to pay for this benefit and jointly promote the establishment of the ecosystem of traceable agricultural products.

Cold chain logistics service providers are subject of cold chain logistics traceable system, and they play an essential role to the cold chain logistics system's integrity and sustainability of cold chain logistics traceable system's construction. As for as enterprises, their decision is not based on consumers' safety. When they believe that revenue is higher than cost, they will provide additional safety information record for consumers by establishing a traceable system. One of the current obstacles about promotion of traceable system is the circulation of agricultural products is small and weak information base. So the initial investment of building a traceable system and day-to-day operating costs are hard to be compensated from the market, which weaken the enthusiasm of enterprises in a degree. Moreover, the use of traceable system is also impacted by the relationships between upstream and downstream enterprises, the competitive environment; the market enterprises pay attention to, consumer pressure on enterprises and legal environment and so on. From the research, we know some agricultural products enterprises tend to cities and high-value agricultural products export trade will invest in building a traceable system out of the consumer pressure and pressure of foreign legal environment. In addition, costs and punishment of the violation of agricultural products' quality and safety also affect its efforts' level in building a traceable system.

\subsection{Path Choice of Cold Chain Logistics Traceable System Implementation for Agricultural Products}

The situation that agricultural products circulation have to through multiple links and the current regulation system in our country determine sector segment management in cold chain logistics traceable system for agricultural products, which leading to hard coordination and inefficient regulation. Meanwhile, small units, large numbers and low degree of information are characteristics in agricultural industry enterprises. In the process of implementing the traceability of agricultural products quality and safety, enterprises should establish traceable information management system and a database, purchase wireless bar code readers, bar code printers and other hardware devices. They also should train their workers and start to use network, and these costs are generally difficult to bear. Existing cold chain logistics traceable system for agricultural products is mainly led by the Government departments, who promote traceable system's establishment and promotion in the form of various types of project funding. Besides, under market conditions of lack of traceable system protection and consumers' lower willingness to pay for traceable agricultural products, so enterprises lack of power and consumers' security demands of agricultural products is also difficult to protect. Based on the implementation status about cold chain logistics traceable system for agricultural products around the world and the bottleneck came across in the process of cold chain logistics traceable system implementation in our country, the implementation's path choice of the massive popularity of traceable system and effective quality supervision must be low cost, high participation and sustainable, namely the construction of ecological system of cold chain logistics traceable system for agricultural products (as shown in the following Figure 5).

The construction of ecological system of cold chain logistics traceable system for agricultural products should regard tracing the main responsibility as the basic requirements, identification as carriers, by means of information, then transfer traceable information to downstream enterprises in production link and share information within the whole supply chain, achieving to the goal of "production records, information can be queried, flow traceability, responsibility can be tracked”. Learning from foreign experience and combined with the develop- 


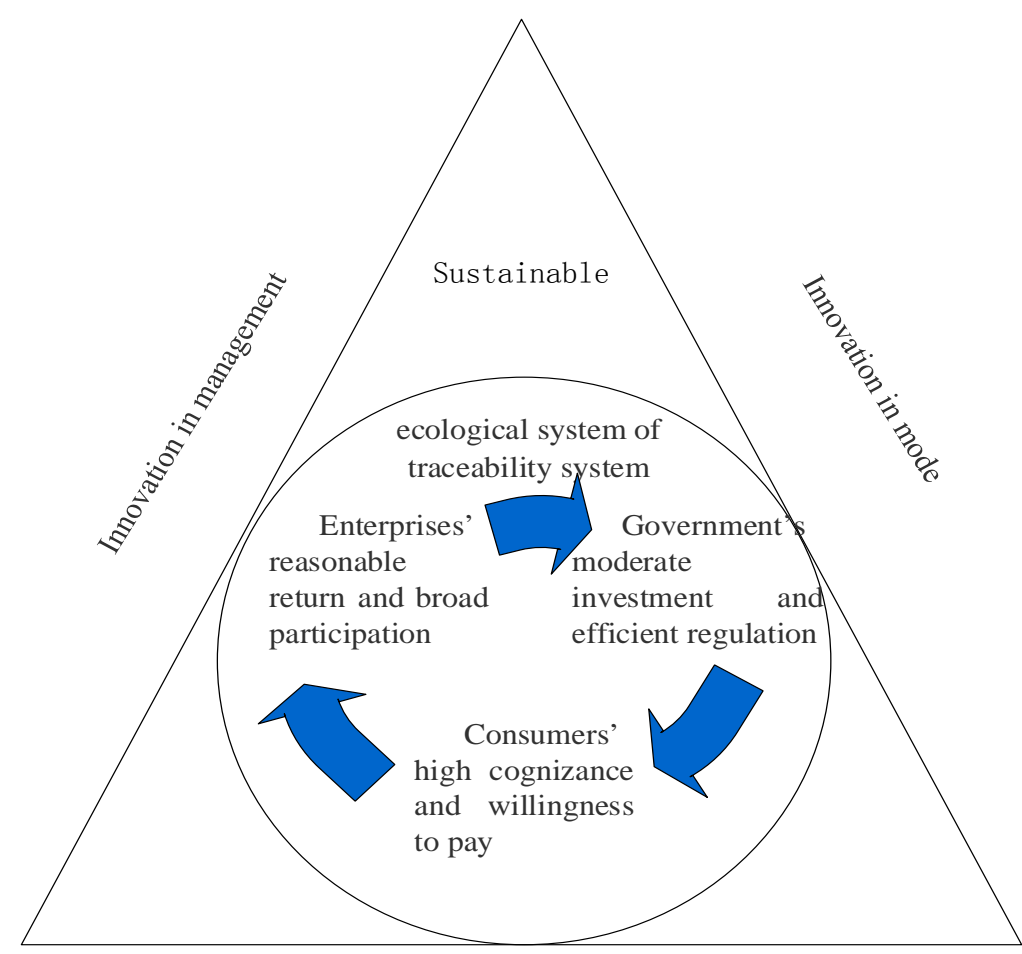

Innovation in technology

Figure 5. Framework of structure's concept about ecological system of cold chain logistics traceable system for agricultural products.

ment in our country, the construction of cold chain logistics traceable system should be driven by the innovation in management, mode and technology and adhere to sustainable path.

\subsubsection{The Innovation in Management}

The Government restricted by the limits of the human, material and financial resources, it cannot supervise and manage all cold chain logistics service provider of agricultural products at all times, so the Government should conduct a innovation in regulatory system and make it cover agricultural products throughout the supply chain, which will lead all subjects involved in the agricultural supply chain run smoothly under the constraint of the system. Secondly, the sector segment management in the cold chain logistics traceable system of agricultural products will lead coordination difficult and inefficient regulatory, and this situation have to be changed. So we require an innovation of management system to break the artificial fragmentation of the supply chain management system for agricultural products, in order to reduce the cost of supply chain information sharing and searching and can also enhance the operability of the traceable system. Existing information management should achieve a breakthrough and existing modes of traceability mainly supported by Government's limited projects funding.

\subsubsection{The Innovation in Mode}

Form the situation of the cold chain traceable system for agricultural products, we know the government investment is still the main mode. The investment returns that enterprises construct traceable system of agricultural products in a short term is not obvious, so they lack of motivation to spontaneous implementation. Enterprises that invest in cold chain logistics traceable system of agricultural products mainly focus on business with high added value and coverage is limited. It is difficult to reach the Government's regulatory requirements on the quality and safety and meet the demands of consumers. Existing modes are hard to address investment channels, power subject, market acceptance, operational sustainability, and many other issues. We have to conduct innovation, so that the Government, enterprises and consumers share the implementation cost fairly, the consumers 
can cognize and are willing to pay, and then enterprises obtain a reasonable return from the market and participate broadly. Besides the Government invests moderately and regulates efficiently.

\subsubsection{The Innovation in Technology}

At present, the implementation of traceable system focuses on front-end information's collection, transfer and queries. But the discovery of the value and market operation about back-end information lack of effective means, and the discovery of the value about back-end information is just one of ways to solve the insufficient implementation power. By Governments' and enterprises' investment into technology research and technical innovation to reduce the costs of traceable system's implementation, enhance the operability of the traceable system and improve the depth and breadth of traceability. Meanwhile, through the development of technology, the value of traceability will be not limited to front-end information's collection, transfer and queries. Discover the back-end information's value with new technology, serving the fine management of enterprises and supply chain collaboration.

\section{Summary}

Based on the connotation and extension of traceable system for agricultural product, this article analyzes its structure and elements of the system, and puts forward that information in logistics is important to the traceable system for agricultural products, which include two core components: distribution, storage and transport links. Immediately following the analysis of the system of implementation models and stakeholders, it aims to introduce the path choice of foundation, and proposes three paths, which provide the theoretical foundation for the current implementation of traceable system, but limits to qualitative analysis, which is the article's shortcomings, and quantitative analysis should be the focus in the future.

\section{Acknowledgements}

The fund project, the National Social Science Fund "The research of fresh agricultural products cold chain logistics management system for the needs of the city" (11BJY111).

\section{References}

[1] Wu, D., Lu, C.Y. and Cheng, H. (2009) Food Quality and Safety Traceable System's Research Progress and Application Prospect of Tea Industry. Agricultural Bulletin, 25, 251-255.

[2] Zheng, H.G. (2012) Food Safety Traceable Systems Research. Chinese Academy of Agricultural Sciences, Beijing.

[3] Zhao, Y.J. (2012) Development Situation of China’s Food Quality and Safety Traceable System. Jilin Agriculture, 2, 200.

[4] Ma, Y. (2011) Honey Quality Traceable System Based on AGENT. Chinese Academy of Agricultural Sciences, Beijing.

[5] Qin, L. and Zhang, P.Y. (2012) Present Situation and Development of Domestic and International Food Safety Traceability. Bar Code and Information System, 2, 19-23.

[6] Ye, J.T. (2010) The Quality and Safety Traceable System Studies Regarding Wholesale Market as the Core of Agricultural Products: Theories and Strategies. Ecological Economy, 10, 110-115.

[7] Yang, X.T., Qian, J.P., Zhao, C.J., et al. (2007) Construction of Vegetable Origin Information Description Language Based on XML and Its Application in Data Exchange. Transactions of the Chinese Society of Agricultural Engineering, 23, 201-205.

[8] Cao, H.L., et al. (2013) Construction of Agricultural Products of Domestic and International Food Safety Traceability. Modern Traditional Chinese Medicine in China, 15, 233-236. 